\title{
Cell Surface Glycosylation Is Required for Efficient Mating of Haloferax volcanii
}

\section{OPEN ACCESS}

Edited by:

Frank T. Robb,

University of Maryland, Baltimore,

United States

Reviewed by:

Aharon Oren,

Hebrew University of Jerusalem, Israe

David L. Bernick,

University of California, Santa Cruz,

United States

Haruyuki Atomi,

Kyoto University, Japan

${ }^{*}$ Correspondence:

Uri Gophna

urigo@tauex.tau.ac.il

tThese authors have contributed equally to this work.

Specialty section:

This article was submitted to

Evolutionary and Genomic

Microbiology,

a section of the journal

Frontiers in Microbiology

Received: 22 May 2017

Accepted: 21 June 2017

Published: 05 July 2017

Citation:

Shalev Y, Turgeman-Grott I, Tamir A, Eichler J and Gophna U (2017) Cell

Surface Glycosylation Is Required for Efficient Mating of Haloferax volcanii. Front. Microbiol. 8:1253.

doi: 10.3389/fmicb.2017.01253

\author{
Yarden Shalev ${ }^{1 \dagger}$, Israela Turgeman-Grott ${ }^{1 \dagger}$, Adi Tamir ${ }^{2}$, Jerry Eichler ${ }^{2}$ and Uri Gophna ${ }^{1 *}$ \\ 'School of Molecular and Cell Biology and Biotechnology, George S. Wise Faculty of Life Sciences, Tel Aviv University, \\ Tel Aviv, Israel, ${ }^{2}$ Department of Life Sciences, Ben-Gurion University of the Negev, Beersheva, Israel
}

Halophilic archaea use a fusion-based mating system for lateral gene transfer across cells, yet the molecular mechanisms involved remain unknown. Previous work implied that cell fusion involves cell-cell recognition since fusion occurs more efficiently between cells from the same species. Long believed to be restricted only to Eukarya, it is now known that cells of all three domains of life perform $\mathrm{N}$-glycosylation, the covalent attachment of glycans to select target asparagine residues in proteins, and that this post-translational modification is common for archaeal cell surface proteins. Here, we show that differences in glycosylation of the Haloferax volcanii surface-layer glycoprotein, brought about either by changing medium salinity or by knocking out key glycosylation genes, reduced mating success. Thus, different glycosylation patterns are likely to underlie mating preference in halophilic archaea, contributing to speciation processes.

Keywords: archaea, glycosylation, lateral gene transfer, mating, surface layer

\section{INTRODUCTION}

The intriguing phenomenon of lateral gene transfer mediated by cell fusion in halophilic archaea (class Halobacteria, phylum Euryarchaeota), also known as mating, has been recognized since the 1980s (Mevarech and Werczberger, 1985; Rosenshine et al., 1989; Rosenshine and Mevarech, 1991; Tchelet and Mevarech, 1993). More recent work has shown that such fusion events can also mediate reciprocal homologous recombination events between different Haloferax species that span hundreds of thousands of base pairs (Naor et al., 2012). Such cell fusion events are not, however, restricted to halophilic archaea. Two species of Thermococcus (class Thermococci, phylum Euryarchaeota), for which no genetic tools exist, were also shown to fuse in the presence of a DNA-interchelating dye (Kuwabara et al., 2005, 2007), indicating a possible connection between DNA exchange and cell fusion that may be more conserved in archaea than previously appreciated.

Cell fusion in the genus Haloferax has been shown to be more efficient within than between species (Naor et al., 2012), implying that a specific cell-cell recognition process is involved in this semi-specificity. Given that the most dominant molecule on the surface of Haloferax cells is the surface-layer (S-layer) glycoprotein, the sole component of the S-layer surrounding the cell (Sumper et al., 1990), it is likely this protein, and potentially its covalently linked glycans, plays some role in the cell fusion process. In $H$. volcanii, the S-layer glycoprotein is subjected to both $\mathrm{N}$ - and O-glycosylation (Sumper et al., 1990; Eichler et al., 2013). Indeed, S-layer 
glycoprotein $\mathrm{N}$-glycosylation occurs at multiple sites that can be affected by environmental cues (Guan et al., 2012; Kaminski et al., 2013a). Since protein-linked sugars are known to mediate cell-cell interactions, as well as cell-matrix interactions, in many eukaryotic cells (for review see Varki and Lowe, 2009), $\mathrm{N}$-glycosylation of haloarchaeal S-layer glycoproteins may play a role in mediating cell-cell recognition within a species and promote initiation of the fusion process.

With this in mind, we examined how differences in $H$. volcanii surface glycosylation influenced cell fusion and showed that environmental and genetic perturbations to this process were able to dramatically affect fusion efficiency. This suggests that surface glycosylation may play a role in cellular recognition and within-species mating preferences in halophilic archaea, thereby affecting gene exchange and speciation processes.

\section{MATERIALS AND METHODS}

\section{Mating Protocol}

As described previously (Naor et al., 2012), cultures of mating partner strains were grown to an $\mathrm{OD}_{600 \mathrm{~nm}}$ of 2.0 , and $1 \mathrm{ml}$ aliquots were drawn from each and applied to a $0.2 \mu \mathrm{m}$ filter connected to a vacuum to eliminate excess medium. The filter was then placed on a Petri dish containing a rich medium (HvYPC medium + thymidine, see below) for $24 \mathrm{~h}$ at $42^{\circ} \mathrm{C}$. The cells were washed, re-suspended in $\mathrm{Hv}$-Ca broth, washed twice more in the same medium, and plated on selective media. Plates were incubated at $42^{\circ} \mathrm{C}$ until colonies were large enough to be counted.

\section{Measuring Cell Fusion Efficiencies}

Mating efficiency was calculated as the number of mating product CFUs on the selective plates divided by the average number of CFUs of each parental strain (for strain genotypes see Table 1). Mating efficiencies of $H$. volcanii incubated at different salt concentrations were calculated using the auxotrophic strains $\mathrm{H} 53(\Delta p y r E, \Delta \operatorname{trp} A)$ and H729 ( $\Delta h d r B)$, selecting for uracil and thymidine as chromosomal markers. Mating efficiencies of strains with defects in $\mathrm{N}$-glycosylation of the S-layer glycoprotein were assessed using episomal plasmid markers. $H$. volcanii $\triangle a g l B$ cells (based on H53 and lacking the oligosaccharyltransferase AglB) were described previously (Abu-Qarn et al., 2007). The $\Delta a g l B \Delta a g l 15$ strain was created by deleting the agl15 gene from $\triangle a g l B$ cells. Gene knockouts were performed according

TABLE 1 | Archaeal strains and plasmids used in this work.

\begin{tabular}{lll}
\hline Source/Reference & Description & Strain/plasmid \\
\hline T. Allers & H. volcanii $\Delta$ hdrB & H729 \\
T. Allers & H. volcanii $\Delta$ pyrE2 $\Delta$ trpA & H53 \\
Abu-Qarn et al., 2007 & & H. volcanii $\Delta$ aglB \\
This study & & H. volcanii $\Delta$ aglB $\Delta$ agl15 \\
Abu-Qarn et al., 2007 & & H. volcanii $\Delta$ aglD \\
Ortenberg et al., 2000 & Resistance to novobiocin & pWL-nov \\
Lam and Doolittle, 1989 & Resistance to mevinolin & pWL-102
\end{tabular}

to the protocols described in (Lam and Doolittle, 1989; BitanBanin et al., 2003). Mating partner strains were transformed using the PEG method (Mevarech and Werczberger, 1985), such that one strain was transformed to carry the plasmid pWL-nov and the other plasmid pWL-102. Selection on plates containing the resistance markers coded by these plasmids, i.e., novobiocin (pWLnov) and mevinolin (pWL102), was then performed.

\section{Culture Conditions}

Haloferax volcanii cells were routinely grown as described (Allers et al., 2010).

\section{Cryo-TEM Analysis of RSO Membrane Vesicles}

Right-side out (RSO) membrane vesicles were prepared from WT glycosylation and $\Delta a g l B \Delta a g l 15$ strain cells and examined by cryo-TEM as described previously (Tamir and Eichler, 2017).

\section{Glycan Detection}

The glycan moiety of the S-layer glycoprotein was glycostained by periodic acid-Schiff's reagent, as previously described (Dubray and Bezard, 1982).

\section{ImageJ Analysis}

SDS-PAGE band intensity was analyzed using ImageJ (Schneider et al., 2012).

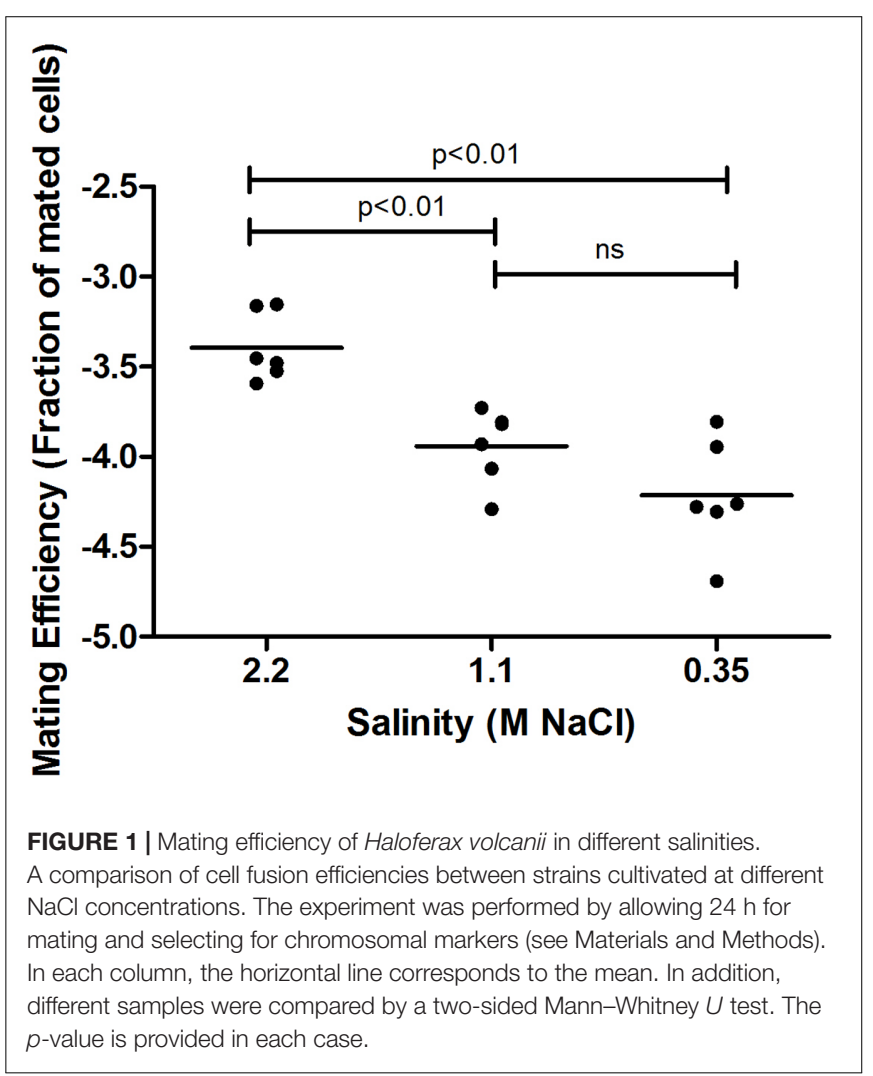




\section{RESULTS}

\section{Mating in Haloferax volcanii Is More Efficient at Higher Salt Concentrations}

Haloarchaea are defined by their ability to grow in hypersaline solutions. Yet, although Haloferax species require high salt $(2.2 \mathrm{M} \mathrm{NaCl})$ concentrations for optimal growth, they are able to replicate in salinities as low as $0.7 \mathrm{M} \mathrm{NaCl}$ and survive prolonged exposure to seawater (Jantzer et al., 2011). Moreover, variation in environmental salt concentrations was previously shown to result in differential processing of $\mathrm{N}$-glycosylation sites in the $H$. volcanii S-layer glycoprotein by glycans containing distinct sugar compositions (Guan et al., 2012). We thus hypothesized that such changes could affect mating efficiency in this species. As such, cultures grown overnight under standard conditions were incubated in fresh medium containing different $\mathrm{NaCl}$ concentrations, defined as optimal, medium and low salinity media $(2.2,1.1$, and $0.35 \mathrm{M} \mathrm{NaCl}$, respectively), prior to mating. In each mating assay, two parental strains, H729 $(\Delta h d r B)$ and H53 ( $\Delta p y r E \Delta \operatorname{trp} A)$, that had been incubated at the same salinity were mated on membrane filters, as previously described (Naor et al., 2012). Mated colonies were selected based on their ability to grow on casamino acid-containing medium lacking uracil and thymidine. Such selection revealed a positive association between mating efficiency and increasing salinity. On average, higher mating efficiency was obtained when cells where incubated in $2.2 \mathrm{M} \mathrm{NaCl}$, as compared to those incubated at $1.1 \mathrm{M} \mathrm{NaCl}$ ( $p<0.01$, two-tailed Mann-Whitney test), with the lowest efficiency being observed in $0.35 \mathrm{M} \mathrm{NaCl}$ (Figure 1). When the H53 and H729 parental strains grown in 3.4 or $1.75 \mathrm{M}$ $\mathrm{NaCl}$ surroundings were allowed to mate, it was sufficient to have only one mating partner initially incubated at the higher salinity for effective mating at a level closer in efficiency to that obtained when both strains were incubated at the optimal salt concentration of $2.2 \mathrm{M} \mathrm{NaCl}$ (Figure 2, $p<0.05$, twotailed Mann-Whitney test, for mating between parents from 3.4 $\mathrm{M} \mathrm{NaCl}$ and parents from 1.75 M NaCl; the difference in efficiency between cases where one parental strain was incubated in $3.4 \mathrm{M} \mathrm{NaCl}$ vs. both strains incubated in $1.75 \mathrm{M} \mathrm{NaCl}$, mating did not reach statistical significance). This implies that at least some aspect of the fusion process in $H$. volcanii is asymmetrical in nature, and that cells that are mating-proficient can display high mating efficiency with non-optimally grown partners.

\section{Interfering with S-Layer Glycoprotein $\mathrm{N}$-Glycosylation Leads to Decreased Mating Efficiency}

As mentioned above, $H$. volcanii modulates the sites and composition of $\mathrm{N}$-linked glycans decorating the S-layer glycoprotein in response to changes in environmental salinity (Guan et al., 2012). Since alterations in salt concentrations also brought about changes in mating frequency, it was hypothesized that modulation of $\mathrm{N}$-linked glycans decorating the S-layer glycoprotein could explain the observed variance in mating efficiency. Specifically, the possibility that differential S-layer glycoprotein $\mathrm{N}$-glycosylation could affect cell-cell recognition and, hence, mating frequency, was considered.

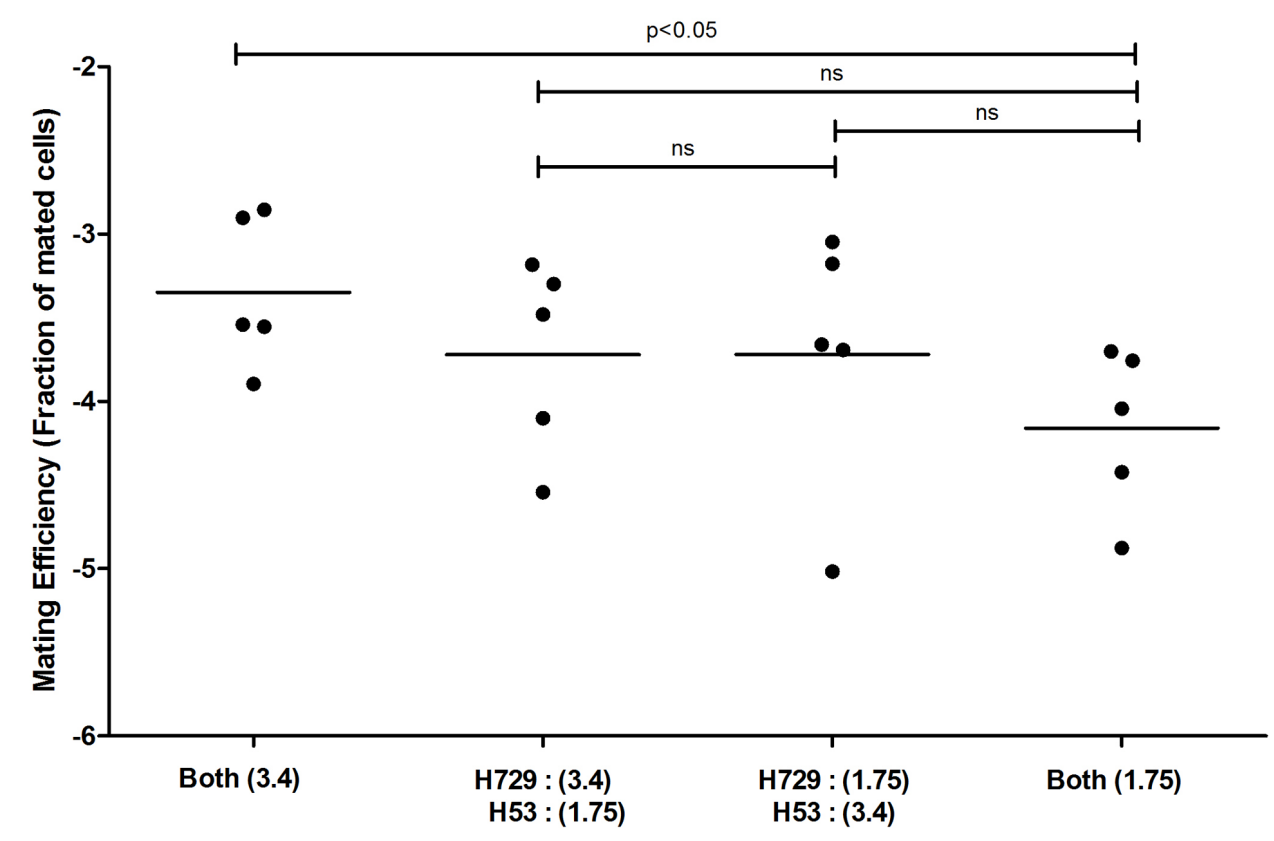

FIGURE 2 | Mating efficiency in Haloferax volcanii of parental strains exposed to different salinities. A comparison of cell fusion efficiencies between strains in which each parent was cultivated separately at different $\mathrm{NaCl}$ concentrations. The experiment was performed by allowing $24 \mathrm{~h}$ for mating and selecting for markers located on the main chromosome (see Materials and Methods). The salinity ( $\mathrm{M} \mathrm{NaCl}$ ) in each case is given in parenthesis. In each column, the horizontal line corresponds to the mean. In addition, different samples were compared by a two-sided Mann-Whitney $U$ test. The $p$-value is provided in each case. 


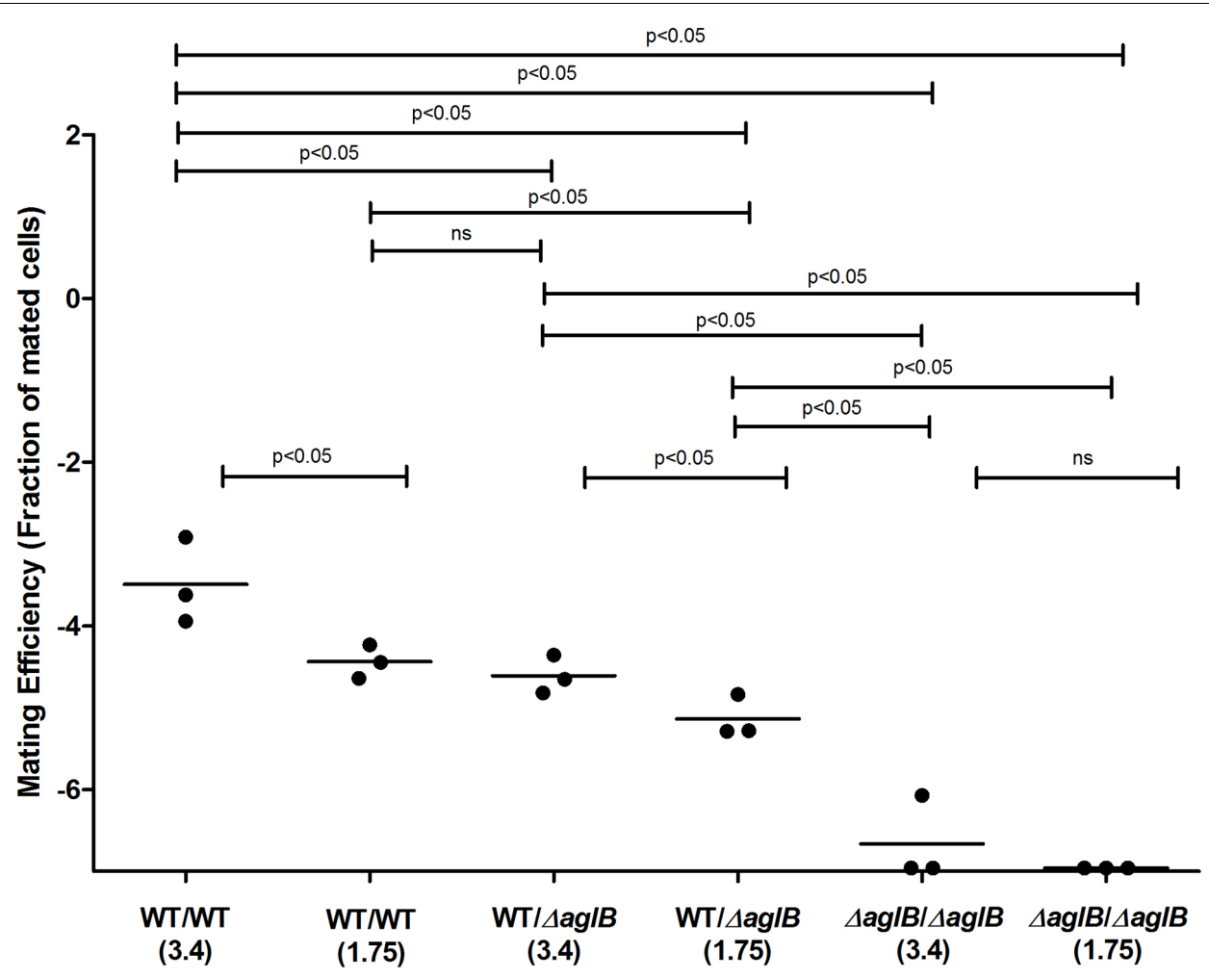

FIGURE 3 | Mating efficiencies of $H$. volcanii with WT glycosylation and $\Delta$ aglB strains. Comparison of cell fusion efficiencies between WT glycosylation strains and strains with S-layer glycoproteins lacking the $\mathrm{N}$-linked pentasaccharide. The salinity ( $\mathrm{M} \mathrm{NaCl}$ ) in each case is given in parenthesis. In each column, the horizontal line corresponds to the mean. In addition, different samples were compared by a one-sided Mann-Whitney $U$ test. The $p$-value is provided in each case.

Previous efforts have defined the $H$. volcanii pathways responsible for the assembly of the pentasaccharide $\mathrm{N}$-linked to at least four S-layer glycoprotein Asn residues and of the tetrasaccharide attached to a distinct Asn residue when cells are grown in only $1.75 \mathrm{M} \mathrm{NaCl}$-containing medium (Eichler et al., 2013; Kaminski et al., 2013a). To test whether deficient S-layer glycoprotein $\mathrm{N}$-glycosylation reduces mating efficiency, $H$. volcanii strain deleted of genes encoding central components of each of these pathways were used. In cells lacking $a g l B$, the oligosaccharyltransferase responsible for delivering the first four sugars of the N-linked pentasaccharide attached to S-layer glycoprotein Asn-13, -83, -274 and -279 from a common dolichol phosphate carrier is absent, such that these residues are not glycosylated (Abu-Qarn et al., 2007; Kandiba et al., 2016). The $\triangle a g l B$ strain was crossed with a strain (H729) that shows wild type glycosylation in mating efficiency assays, selecting for mating products based on plasmid markers. The mating efficiency experiments were performed at two different $\mathrm{NaCl}$ concentrations (i.e., in the presence of 1.75 or $3.4 \mathrm{M} \mathrm{NaCl}$ ), conditions in which two different patterns of N-linked glycosylation of the S-layer glycoprotein occur (Guan et al., 2012). Mating efficiencies in WT glycosylation strain cells containing AglB were higher when the cells were incubated at $3.4 \mathrm{M} \mathrm{NaCl}$, as compared to those in the less saline $1.75 \mathrm{M} \mathrm{NaCl}$-containing medium. The same trend was observed when mating of the WT and $\triangle a g l B$ strain was assayed. WT/ $\triangle a g l B$ strain mating was, on average, less efficient than WT/WT $(p<0.05$ in either salinity, one-tailed MannWhitney test) mating performed at same salt concentrations (Figure 3). The most profound effect on mating efficiency was observed when crossing $\triangle a g l B$ cells with $\triangle a g l B$ cells in either 1.75 or $3.4 \mathrm{M} \mathrm{NaCl}$-containing medium. Here, mating efficiency was remarkably low ( $p<0.05$, one-tailed MannWhitney test, in either salinity, compared to WT/WT and $\mathrm{WT} / \Delta a g l B$ mating efficiencies), with only few, and often no mating products being observed after 140-160 h of incubation. This indicates that in $H$. volcanii, a direct link exists between $\mathrm{S}$-layer glycoprotein $\mathrm{N}$-glycosylation and mating by fusion, with partial dominance of the WT N-glycosylation phenotype in mating.

While the $H$. volcanii S-layer glycoprotein Asn-13, -83, 274 and -279 positions are modified by a pentasaccharide comprising a glucose, a glucuronic acid, a galacturonic acid, a methylated glucuronic acid and a mannose when cells are grown in the presence of either 1.75 or $3.4 \mathrm{M} \mathrm{NaCl}$, the Asn-498 position is modified by a distinct tetrasaccharide comprising a sulfated hexose, two hexoses and rhamnose in cells grown in $1.75 \mathrm{M} \mathrm{NaCl-containing} \mathrm{medium} \mathrm{(Kaminski}$ et al., 2013a; Kandiba et al., 2016). Furthermore, it has been shown that in cells deleted of genes involved in the assembly of the $\mathrm{N}$-linked pentasaccharide grown in $3.4 \mathrm{M} \mathrm{NaCl}$, the 'low salt' tetrasaccharide attached to Asn-498, normally only 


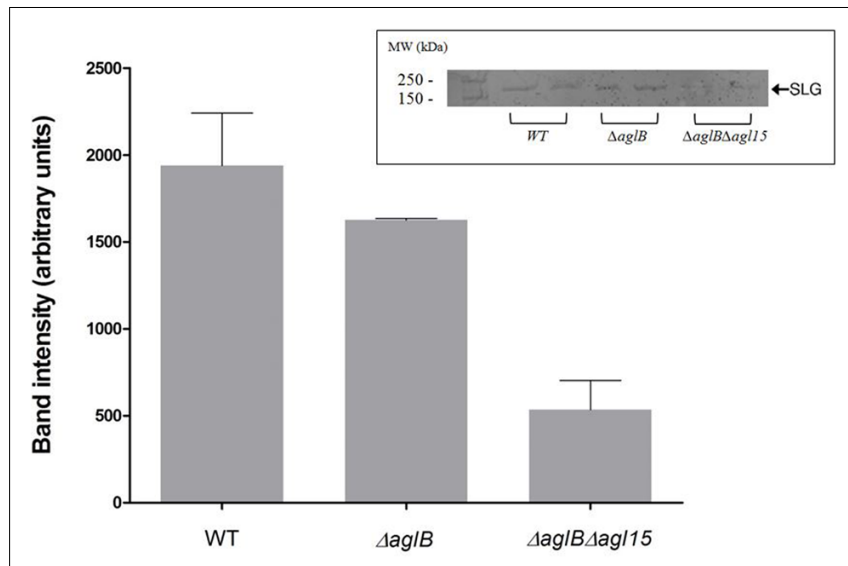

FIGURE 4 | S-layer glycoprotein glycosylation. S-layer glycoproteins from a strain with WT glycosylation, $\Delta$ aglB cells and $\Delta$ aglB $\Delta$ agl 15 cells (two repeats of each strain), as revealed by SDS-PAGE and staining with periodic acid-Schiff's reagent are shown in the inset (upper right corner). The positions of molecular weight markers are shown on the left, while the position of the S-layer glycoprotein is shown on the right. Glycostained band density was analyzed using ImageJ (see Materials and Methods). The error bar represents the standard deviation.

observed upon growth in $1.75 \mathrm{M} \mathrm{NaCl}$, was detectable, despite the elevated surrounding salinity (Kaminski et al., 2013a). Therefore, deletion of $a g l B$ may lead to increased activity of the second $\mathrm{N}$-glycosylation pathway, normally functional at the lower salinity, at higher salt levels, too. To, therefore, rule out the possibility that aberrant $\mathrm{N}$-glycosylation, rather than reduced $\mathrm{N}$-glycosylation, was responsible for the impaired mating phenotype observed using the $\triangle a g l B$ strain, a double deletion strain lacking both $a g l B$ and $a g l 15$ was generated. Agl15 is thought to participate in the translocation of dolichol phosphate bearing the 'low salt' tetrasaccharide across the membrane, such that deletion of the encoding gene leads to the absence of this glycan on the S-layer glycoprotein (Kaminski et al., 2013a). As expected, when the protein content of $\triangle a g l B \Delta a g l 15$ cells was separated on SDS-PAGE and glycostained using periodic acid-Schiff's reagent, a drastic reduction in S-layer glycoprotein glycosylation was observed (Figure 4). These underglycosylated cells also showed very low, or even undetectable, mating efficiency, even when grown at the higher salinity for mating (3.4 M NaCl; Figure 5) and incubated for about $210 \mathrm{~h}$ (about 3 days longer than the experiment described in Figure 3). It would thus seem that the dramatic decline in mating efficiency $(p<0.05$, one-tailed Mann-Whitney test) seen with the double mutant strain is due to a lack of N-glycosylation of the S-layer glycoprotein comprising the S-layer, rather than differences in S-layer glycoprotein N-linked glycan composition.

\section{S-Layer Integrity Is Compromised in Membrane Vesicles Prepared from Cells Lacking aglB and agl15}

To better understand how the compromised N-glycosylation seen in the $\Delta a g l B \Delta a g l 15$ strain could lead to reduced mating, RSO membrane vesicles were prepared from WT glycosylation and $\Delta a g l B \Delta a g l 15$ strain cells and examined by cryo-transmission electron microscopy (cryo-TEM). In agreement with earlier studies (Tamir and Eichler, 2017), RSO vesicles prepared from WT glycosylation strain cells clearly showed both the plasma membrane and the surrounding concentric S-layer. The S-layer was intact, regularly ordered and equidistant from the enclosed membrane vesicle at all points (Figure 6A). In contrast, whereas membrane vesicles of similar dimensions as obtained from WT glycosylation strain cells were generated from the double mutant strain, in the vast majority, no surrounding S-layer was seen. Instead, a poorly ordered and more diffuse structure

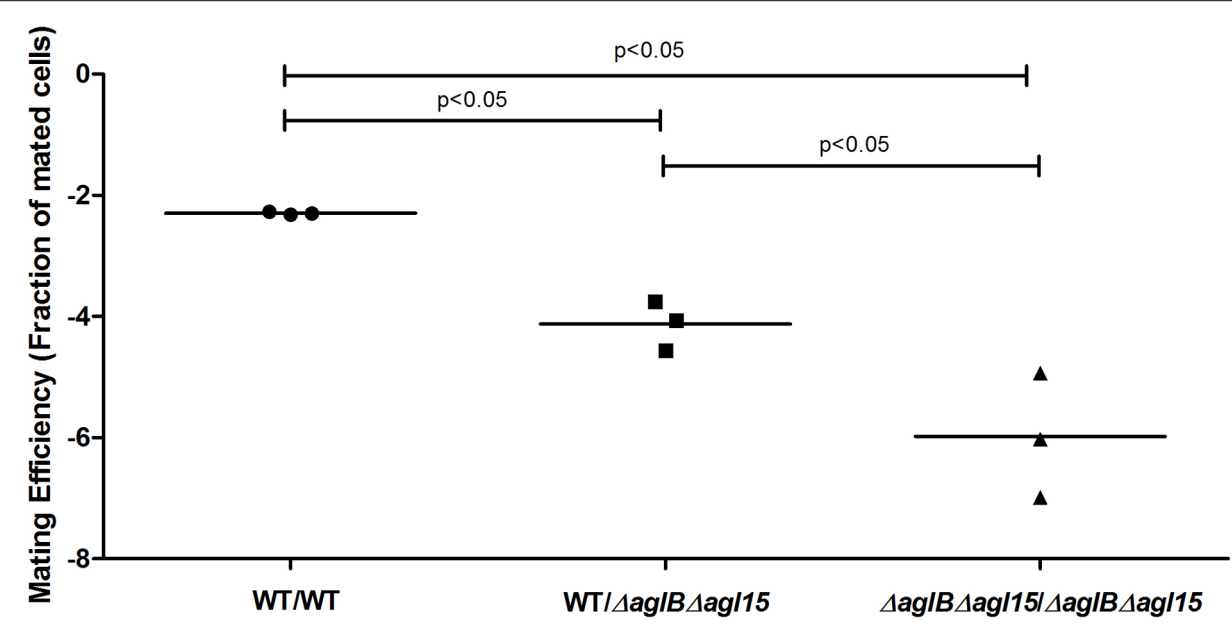

FIGURE 5 | Mating efficiencies of $H$. volcanii cells presenting WT glycosylation with $\Delta$ aglB $\Delta$ agl15 cells. A comparison of cell fusion efficiencies between WT glycosylation strains and strains lacking enzymes that respectively mediate or contribute to the attachment of the pentasaccharide and the low salt tetrasaccharide to the S-layer glycoprotein. The salinity used was 3.4 M NaCl. In each column, the horizontal line corresponds to the mean. In addition, different samples were compared by a one-sided Mann-Whitney $U$ test. The $p$-value is provided in each case. 


\section{A}

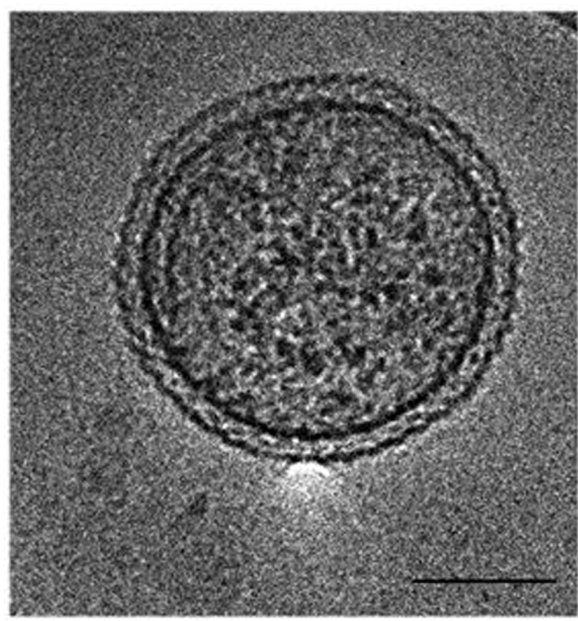

B

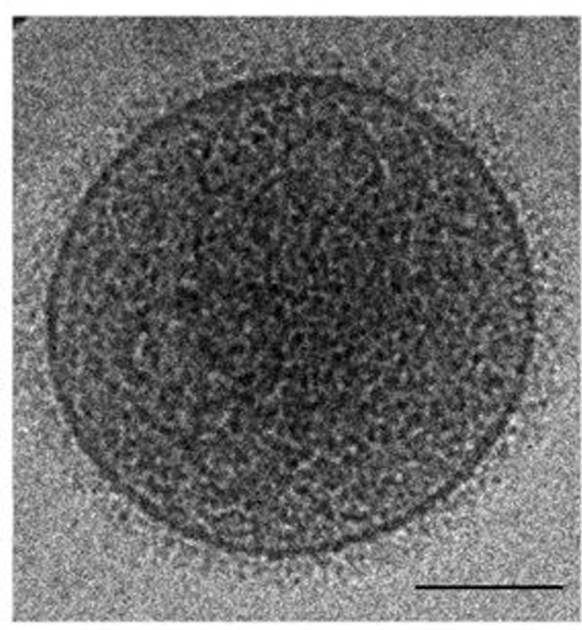

C

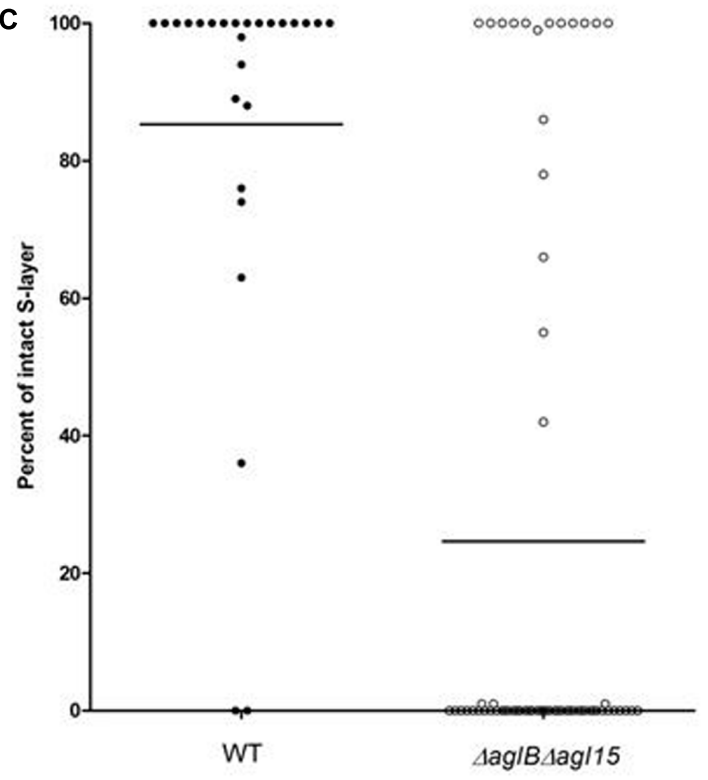

FIGURE 6 | Cryo-transmission electron microscopy of right-side-out membrane vesicles. The S-layer is compromised in RSO membrane vesicles prepared from H. volcanii $\Delta$ aglB $\Delta$ agl15. (A,B) Electron micrograph of a representative RSO membrane vesicles derived from $H$. volcanii cells of the WT glycosylation strain (A) and the $\Delta$ aglB $\Delta$ agl15 strain (B). In each panel, the bar represents $100 \mathrm{~nm}$. (C) The percentages of intact S-layer in RSO membrane vesicles prepared from cells of the WT glycosylation strain (left, full symbols; $n=26$ ) and the $\Delta$ aglB $\Delta$ agl15 strain (right, open symbols; $n=62$ ). In each column, the average (horizontal line) and the distribution of values collected from each vesicle population are presented.

surrounded these vesicles (Figure 6B). Statistical analysis of the extent of S-layer coverage of RSO vesicles prepared from the WT glycosylation and $\Delta a g l B \Delta a g l 15$ strains confirmed these claims, with the percentage of S-layer coverage of parent strainderived vesicles being $85.4 \%$ [ $\pm 29.2 \%(S D) ; n=26]$, as opposed to $24.8 \%( \pm 41.4 \% ; n=62)$ in $\Delta a g l B \Delta a g l 15$ strain-derived vesicles. As such, it would seem that the S-layer in cells lacking AglB and Agl15 is less sturdy than in WT glycosylation cells, as reflected in how poorly this structure remained intact during the preparation of RSO vesicles from the double mutant strain.

\section{Minor Changes in S-Layer Glycosylation Do Not Decrease Mating Efficiency}

The N-glycosylation pathway mutants generated above demonstrated drastic effects on S-layer glycoprotein glycosylation. To now test whether minor changes in $\mathrm{N}$-glycosylation also perturbed mating, mating involving a $H$. volcanii strain deleted of aglD, encoding the glycosyltransferase that adds the final sugar of the $\mathrm{N}$-linked pentasaccharide, mannose, to its own dolichol phosphate carrier (Abu-Qarn et al., 2007; Guan et al., 2010), was considered. When mating two $\Delta a g l D$ cells, a slight increase in mating efficiency was observed, relative to the WT glycosylation strain ( $p=0.1$, two-tailed Mann-Whitney test, Figure 7). In contrast, a slight decrease in average mating efficiency was observed when cells of the WT glycosylation and $\triangle a g l D$ strains were crossed, which did not reach statistical significance. This finding shows that the absence or presence of the last sugar of the $\mathrm{N}$-linked pentasaccharide decorating the S-layer glycoprotein affects recognition between two $H$. volcanii cells, albeit to only a moderate extent. 


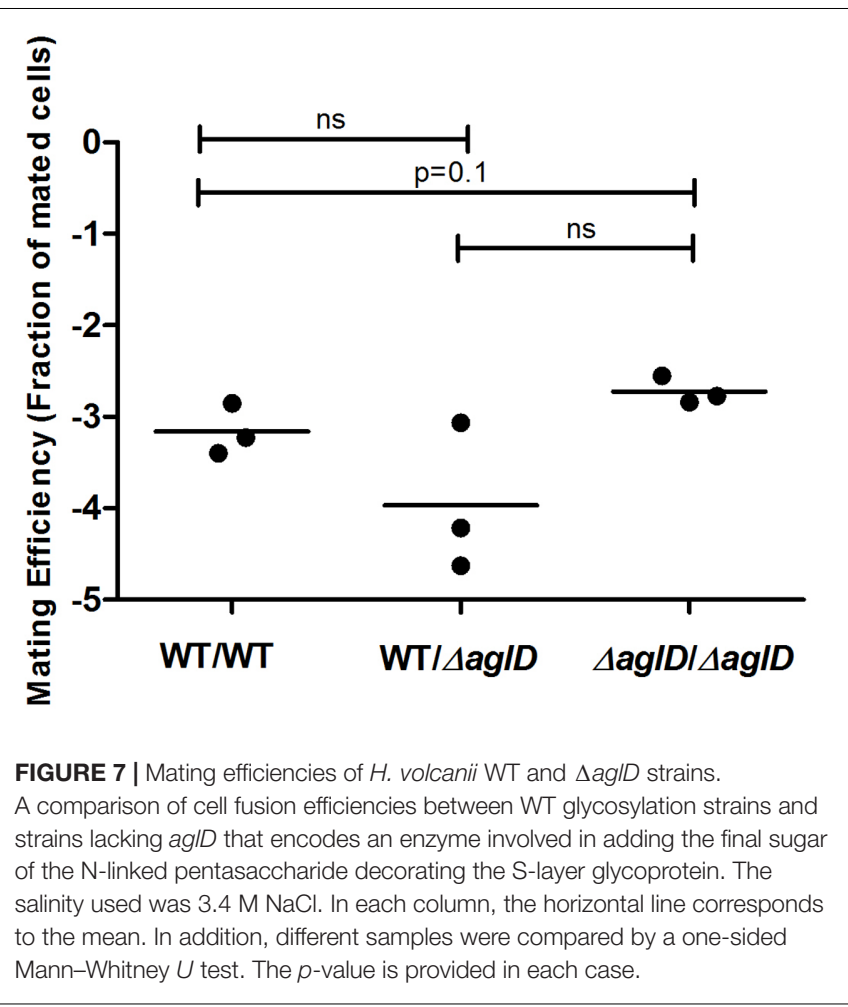

\section{DISCUSSION}

Here, we showed that haloarchaeal fusion is affected by environmental exposure, and that higher mating efficiency is observed under high salt conditions. Given that previous work showed that mating frequently occurs in biofilms (Chimileski et al., 2014), it is likely that in their natural environment, $H$. volcanii cells fuse primarily on high-salt biofilms, such as those found on salt-covered rocks, where mating is relatively efficient.

Apart from environmental exposure, mating efficiency is also affected by the genetic capacity for S-layer glycosylation. Our results show that S-layer glycan deficiency dramatically decreased mating ability. When neither the tetrasaccaride nor the pentasaccaride were present on the S-layer glycoprotein comprising the S-layer, far fewer cell fusion events were observed. Thus, surface glycosylation is likely to be a pre-requisite for mating in Haloferax. However, we found that having one matingproficient partner appears to be sufficient, since the effects of incubation of one partner in low salinity, be it an $\operatorname{aglB}$, or a combined $a g l B$ and $a g l 15$ deletion strain, on mating with the WT strain were only semi-recessive.

One explanation for the effect of loss of glycosylation on mating efficiency could be related to structural considerations (Imperiali and O'Connor, 1999). This would explain why the presence of an intact and sturdy S-layer, as seen in WT glycosylation cells, better enabled cell fusion interactions than did the $\mathrm{N}$-glycosylation mutants examined, with their less hardy S-layer (Figure 6). In contrast to what was seen upon total loss of $\mathrm{N}$-glycosylation, we observed that minor changes in $\mathrm{N}$-glycosylation, such as those generated by a deletion of aglD, did not decrease and even slightly increased cell fusion efficiency (Figure 7). One reason for this could be that the methylated glucuronic acid at position four of the pentasaccharide, exposed in the absence of the final sugar (mannose) in $\triangle a g l D$ cells (Abu-Qarn et al., 2007; Kandiba et al., 2016), mediates stronger interactions with the S-layer of neighboring cells. However, recent work showed that modification of the S-layer glycoprotein by only the first four sugars of the $\mathrm{N}$-linked pentasaccharide resulted in a more protease-susceptible conformation (Tamir and Eichler, 2017) than when the same protein was modified by the complete pentasaccharide or by N-linked glycans containing three or fewer sugars. Thus, it is possible that the fifth sugar (mannose) somehow masks charges associated with other sugars in the N-linked pentasaccharide (Tamir and Eichler, 2017), thereby resulting in improved binding between cells.

The partial tolerance of mating by fusion to incompatible sugar presentation on the S-layer glycoprotein may also explain the relatively high efficiency with which different species of Haloferax were shown to mate (Naor and Gophna, 2013), despite differences in S-layer glycan composition (Cohen-Rosenzweig et al., 2014). The semi-dominant effect of glycosylation on mating strongly suggests a mechanism in which a protein or lipid ligand in one cell interacts with a glycosylated receptor on its partner (or vice versa) in the cell-cell recognition step required to initiate fusion (Naor and Gophna, 2013). Interacting with a specific surface sugar could thus contribute to the preference for fusion between cells of the same species (conspecific fusion), as previously observed when comparing fusion efficiencies between $H$. volcanii and $H$. mediterranei (Naor et al., 2012). Since glycosylation clusters have been frequently horizontally transferred in halophilic archaea (Kaminski et al., 2013b), the changes in S-layer glycosylation that such acquired clusters can bring could change mating preferences and result in rapid lineage diversification leading to sympatric speciation.

\section{AUTHOR CONTRIBUTIONS}

IT-G, UG, and YS conceived the study, IT-G and YS designed, generated and characterized mutant strains and plasmids, IT-G, YS, and UG designed experiments, IT-G, YS, and AT performed experiments and analyzed data, YS, IT-G, UG, and JE wrote the manuscript. All authors read and commented on the manuscript.

\section{FUNDING}

This work was funded by Israel Science Foundation grants to UG [535/15] and to JE [109/16].

\section{ACKNOWLEDGMENT}

The authors would like to thank members of the Gophna lab for their advice and encouragement. 


\section{REFERENCES}

Abu-Qarn, M., Yurist-Doutsch, S., Giordano, A., Trauner, A., Morris, H. R., Hitchen, P., et al. (2007). Haloferax volcanii AglB and AglD are involved in $\mathrm{N}$-glycosylation of the S-layer glycoprotein and proper assembly of the Surface Layer. J. Mol. Biol. 374, 1224-1236. doi: 10.1016/j.jmb.2007.10.042

Allers, T., Barak, S., Liddell, S., Wardell, K., and Mevarech, M. (2010). Improved strains and plasmid vectors for conditional overexpression of His-tagged proteins in Haloferax volcanii. Appl. Environ. Microbiol. 76, 1759-1769. doi: 10.1128/AEM.02670-09

Bitan-Banin, G., Ortenberg, R., and Mevarech, M. (2003). Development of a gene knockout system for the halophilic archaeon Haloferax volcanii by use of the pyrE gene. J. Bacteriol. 185, 772-778. doi: 10.1128/JB.185.3.772-778. 2003

Chimileski, S., Franklin, M. J., and Papke, R. (2014). Biofilms formed by the archaeon Haloferax volcanii exhibit cellular differentiation and social motility, and facilitate horizontal gene transfer. BMC Biol. 12:65. doi: 10.1186/s12915014-0065-5

Cohen-Rosenzweig, C., Guan, Z., Shaanan, B., and Eichler, J. (2014). Substrate promiscuity: AglB, the archaeal oligosaccharyltransferase, can process a variety of lipid-linked glycans. Appl. Environ. Microbiol. 80, 486-496. doi: 10.1128/ AEM.03191-13

Dubray, G., and Bezard, G. (1982). A highly sensitive periodic acidsilver stain for 1,2-diol groups of glycoproteins and polysaccharides in polyacrylamide gels. Anal. Biochem. 119, 325-329. doi: 10.1016/0003-2697(82) 90593-0.

Eichler, J., Arbiv, A., Cohen-Rosenzweig, C., Kaminski, L., Kandiba, L., and Konrad, Z. (2013). N-glycosylation in Haloferax volcanii: adjusting the sweetness. Front. Microbiol. 4:403. doi: 10.3389/fmicb.2013.00403

Guan, Z., Naparstek, S., Calo, D., and Eichler, J. (2012). Protein glycosylation as an adaptive response in Archaea: growth at different salt concentrations leads to alterations in Haloferax volcanii S-layer glycoprotein $\mathrm{N}$-glycosylation. Environ. Microbiol. 14, 743-753. doi: 10.1111/j.1462-2920.2011.02625.x

Guan, Z., Naparstek, S., Kaminski, L., Konrad, Z., and Eichler, J. (2010). Distinct glycan-charged phosphodolichol carriers are required for the assembly of the pentasaccharide N-linked to the Haloferax volcanii S-layer glycoprotein. Mol. Microbiol. 78, 1294-1303. doi: 10.1111/j.1365-2958.2010. 07405.x

Imperiali, B., and O'Connor, S. E. (1999). Effect of N-linked glycosylation on glycopeptide and glycoprotein structure. Curr. Opin. Chem. Biol. 3, 643-649. doi: 10.1016/S1367-5931(99)00021-6

Jantzer, K., Zerulla, K., and Soppa, J. (2011). Phenotyping in the archaea: optimization of growth parameters and analysis of mutants of Haloferax volcanii. FEMS Microbiol. Lett. 322, 123-130. doi: 10.1111/j.1574-6968.2011. 02341.x

Kaminski, L., Guan, Z., Yurist-Doutsch, S., and Eichler, J. (2013a). Two distinct $\mathrm{N}$-glycosylation pathways process the Haloferax volcanii S-layer glycoprotein upon changes in environmental salinity. MBio 4:e716-13. doi: 10.1128/mBio. 00716-13

Kaminski, L., Lurie-Weinberger, M. N., Allers, T., Gophna, U., and Eichler, J. (2013b). Phylogenetic- and genome-derived insight into the evolution of N-glycosylation in Archaea. Mol. Phylogenet. Evol. 68, 327-339. doi: 10.1016/ j.ympev.2013.03.024

Kandiba, L., Lin, C.-W., Aebi, M., Eichler, J., and Guerardel, Y. (2016). Structural characterization of the $\mathrm{N}$-linked pentasaccharide decorating glycoproteins of the halophilic archaeon Haloferax volcanii. Glycobiology 26, 745-756. doi: 10.1093/glycob/cww014

Kuwabara, T., Minaba, M., Iwayama, Y., Inouye, I., Nakashima, M., Marumo, K., et al. (2005). Thermococcus coalescens sp. nov., a cell-fusing hyperthermophilic archaeon from Suiyo Seamount. Int. J. Syst. Evol. Microbiol. 55, 2507-2514. doi: 10.1099/ijs.0.63432-0

Kuwabara, T., Minaba, M., Ogi, N., and Kamekura, M. (2007). Thermococcus celericrescens sp. nov., a fast-growing and cell-fusing hyperthermophilic archaeon from a deep-sea hydrothermal vent. Int. J. Syst. Evol. Microbiol. 57, 437-443. doi: 10.1099/ijs.0.64597-0

Lam, W. L., and Doolittle, W. F. (1989). Shuttle vectors for the archaebacterium Halobacterium volcanii. Proc. Natl. Acad. Sci. U.S.A. 86, 5478-5482.

Mevarech, M., and Werczberger, R. (1985). Genetic transfer in Halobacterium volcanii. J. Bacteriol. 162, 461-462.

Naor, A., and Gophna, U. (2013). Cell fusion and hybrids in Archaea: prospects for genome shuffling and accelerated strain development for biotechnology. Bioengineered 4, 126-129. doi: 10.4161/bioe.22649

Naor, A., Lapierre, P., Mevarech, M., Papke, R. T., and Gophna, U. (2012). Low species barriers in halophilic archaea and the formation of recombinant hybrids. Curr. Biol. 22, 1444-1448. doi: 10.1016/j.cub.2012.05.056

Ortenberg, R., Rozenblatt-Rosen, O., and Mevarech, M. (2000). The extremely halophilic archaeon Haloferax volcanii has two very different dihydrofolate reductases. Mol. Microbiol. 35, 1493-1505.

Rosenshine, I., and Mevarech, M. (1991). "The kinetic of the genetic exchange process in Halobacterium volcanii mating," in General and Applied Aspects of Halophilic Microorganisms, ed. F. Rodriguez-Valera (New York, NY: Springer), 265-270.

Rosenshine, I., Tchelet, R., and Mevarech, M. (1989). The mechanism of DNA transfer in the mating system of an archaebacterium. Science 245, 1387-1389. doi: $10.1126 /$ science. 2818746

Schneider, C. A., Rasband, W. S., and Eliceiri, K. W. (2012). NIH Image to ImageJ: 25 years of image analysis. Nat. Methods 9, 671-675. doi: 10.1038/nmeth.2089

Sumper, M., Berg, E., Mengele, R., and Strobel, I. (1990). Primary structure and glycosylation of the S-layer protein of Haloferax volcanii. J. Bacteriol. 172, 7111-7118. doi: 10.1128/JB.172.12.7111-7118.1990

Tamir, A., and Eichler, J. (2017). N-glycosylation is important for proper Haloferax volcanii S-Layer stability and function. Appl. Environ. Microbiol. 83, e3152e3116. doi: 10.1128/AEM.03152-16

Tchelet, R., and Mevarech, M. (1993). Interspecies genetic transfer in halophilic Archaebacteria. Syst. Appl. Microbiol. 16, 578-581. doi: 10.1016/S0723-2020(11) 80328-0

Varki, A., and Lowe, J. B. (2009). Biological Roles of Glycans. Cold Spring Harbor, NY: Cold Spring Harbor Laboratory Press.

Conflict of Interest Statement: The authors declare that the research was conducted in the absence of any commercial or financial relationships that could be construed as a potential conflict of interest.

Copyright (C) 2017 Shalev, Turgeman-Grott, Tamir, Eichler and Gophna. This is an open-access article distributed under the terms of the Creative Commons Attribution License (CC BY). The use, distribution or reproduction in other forums is permitted, provided the original author(s) or licensor are credited and that the original publication in this journal is cited, in accordance with accepted academic practice. No use, distribution or reproduction is permitted which does not comply with these terms. 